\title{
Política social: subsídios estatísticos sobre a pobreza e acesso a programas sociais no Brasil
}

\author{
JUAREZ RUBENS BRANDÄOLOPES
}

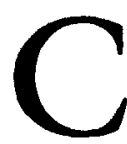

OM ESTE DOCUMENTO quero apresentar um modo de fazer diagnósticos sócio-econômicos da pobreza, úteis para a formulação de políticas e programas sociais. Entre os resultados deste éxercício destacam-se a heterogeneidade da pobreza em termos de estruturas familiares regionais e de sua gravidade a necessidade de distinguir-se situaçóes de pobreza estrutural de outras, de pobreza mais recente, ocasionadas pela perda de emprego ou de renda durante os anos recessivos dos últimos 15 anos.

\section{Evolução da pobreza}

Estudo de Romão (1991), utilizando dados censais e Pnads e usando linhas de pobreza, definidas grosso modo da mesma maneira como é feito no presente estudo (1), fornece-nos as seguintes proporçōes de pobres para todo o país, nas datas dos censos: $\operatorname{Em} 1960,41,4 \%$; em 1970, 39,3\%; em 1980, 24,4\%. Com a recessão no início dos anos $\mathbf{8 0}$, elevou-se rapidamente a proporção de pobres: em 1983 estávamos novamente no nível de 1960: 41,9\%. A recuperação econômica iniciada em 1985, que culminou com o boom do Plano Cruzado, fez cair rapidamente a proporção de pobres: em 1986 ela desceu para 28,4\%. Nos anos seguintes, a escalada da inflação e a deterioração econômica, com os efeitos recessivos de planos anti-inflacionários, elevaram de novo a taxa: 35,9 em 1987 e 39,3\% em 1988, voltando ao nível de 1970 (2).

\section{Dimensionamento e caracterização da pobreza}

As tabelas 2 e 3 apontam para as dimensóes mais amplas da questão da pobreza no Brasil. Há mais de 8,6 milhões de domicílios pobres urbanos no país (2,8 milhões no nível de indigência), além de 3,2 milhōes de rurais, provavel- 
mente subestimados (3). Um em cada três domicílios urbanos é pobre; nas zonas rurais esta proporção chega a quase um em dois. Destaca-se a concentraçáo das crianças de zero a três anos nos lares pobres: quase a metade das crianças urbanas são pobres. Com o cruzamento do indicador de necessidades básicas pode-se ter uma aproximação da pobreza estrutural (aqueles que sendo pobres - indigentes ou não -, têm as suas necessidades básicas insatisfeitas); essa pobreza estrutural seria menos variável com a conjuntura econômica e apenas lentamente poderia. ser aliviada. Estão em tal situaçâo $12,5 \%$ dos domicílios urbanos, somando mais de 3,2 milhões de domicílios.

Tabela 1

Brasil 1989. Domicílios rurais e urbanos, segundo as várias regiões

Em milhares

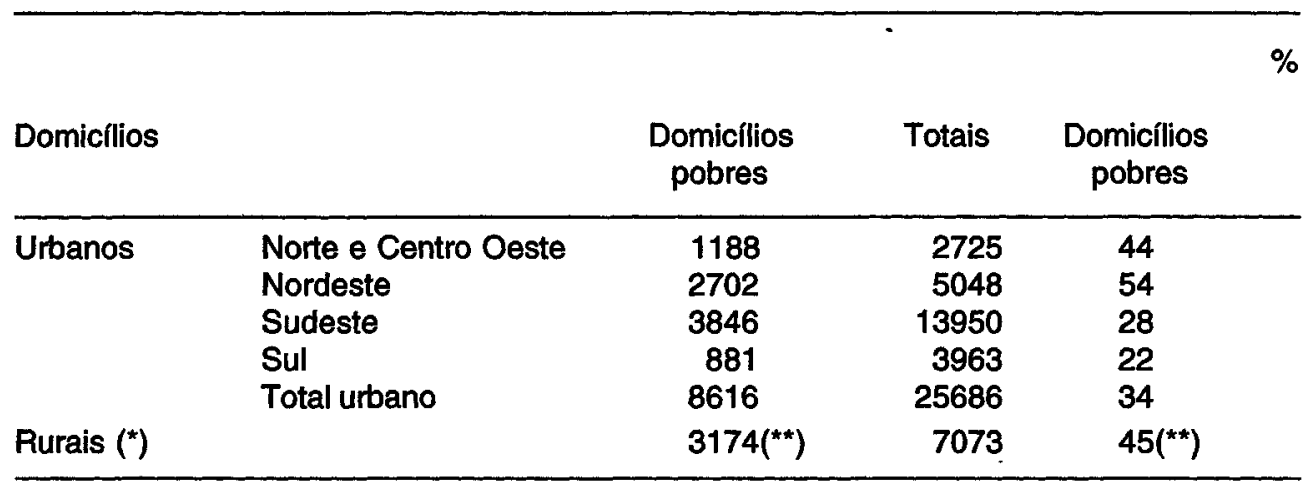

(*) A zona rural da região Norte não foi coberta pelo Pnsn; além disso, não havia dados suficientes para se calcular a linha de pobreza rural para o Centro-Oeste. Assim, estão incluídas aqui só as regiōes Nordeste, Sudeste e Sul.

(*) Provavelmente muito subestimados (ver nota 3).

Fonte: Pnsn; elaboração Nepp/Unicamp, 1993.

Tabela 2

Brasil urbano, 1989. Distribuição dos domicílios segundo indicador de necessidades básicas (*) e segundo níveis de pobreza

\begin{tabular}{|c|c|c|c|c|c|}
\hline & INB & 1 & $\mathrm{Pn}$ & Np & Total \\
\hline $\begin{array}{l}\text { Número de } \\
\text { domicílios } \\
\text { (milhares) }\end{array}$ & $\begin{array}{l}\text { NBI } \\
\text { NBS }\end{array}$ & $\begin{array}{l}1.503,0 \\
1.324,2\end{array}$ & $\begin{array}{l}1.707,7 \\
4.069,0\end{array}$ & $\begin{array}{r}1.624,9 \\
15.394,7\end{array}$ & $\begin{array}{r}4.835,6 \\
20.787,9\end{array}$ \\
\hline $\begin{array}{l}\text { Distribuição } \\
\text { percentual } \\
\text { dos domicllios }\end{array}$ & $\begin{array}{l}\text { NBI } \\
\text { NBS }\end{array}$ & $\begin{array}{l}5,9 \\
5,2\end{array}$ & $\begin{array}{r}6,7 \\
15,9\end{array}$ & $\begin{array}{r}6,3 \\
60,1\end{array}$ & $\begin{array}{l}18,9 \\
81,1\end{array}$ \\
\hline
\end{tabular}

INB - índice de necessidades básicas; 1 -indigentes, Pn - pobres não-indigentes, e Np - não-pobres. (") ver nota 1.

Fonte: Pnsn; elaboração Nepp/Unicamp, 1993. 
Tabela 3

Brasil urbano, 1989. Distribuição percentual de dados básicos segundo níveis de indigência e pobreza, pelas várias regiões

\begin{tabular}{lrrrrr}
\hline Região & $\mathrm{I}$ & $\mathrm{Pn}$ & $\mathrm{Np}$ & \multicolumn{1}{c}{ Total } & Total ('000s) \\
\hline Norte e Centro-Oeste & & & & & \\
Domicílios & 13,4 & 30,2 & 56,4 & 100,0 & $2.725,4$ \\
Pessoas & 16,2 & 33,1 & 50,6 & 100,0 & $12.222,8$ \\
Crianças (0 a 3) & 23,0 & 34,3 & 42,7 & 100,0 & $1.206,3$ \\
Nordeste & & & & & \\
Domicílios & 23,0 & 30,5 & 46,5 & 100,0 & $5.048,3$ \\
Pessoas & 29,4 & 29,7 & 40,9 & 100,0 & $23.307,1$ \\
Crianças (0 a 3) & 40,8 & 27,6 & 31,6 & 100,0 & $2.203,2$ \\
& & & & & \\
Sudeste & & & & & \\
Domicílios & 7,5 & 20,1 & 72,4 & 100,0 & $13.949,6$ \\
Pessoas & 8,4 & 23,1 & 68,5 & 100,0 & $53.988,6$ \\
Crianças (0 a 3) & 16,9 & 28,8 & 54,3 & 100,0 & $4,259,8$ \\
Sul & & & & & \\
Domicílios & & & & & \\
Pessoas & 6,6 & 15,6 & 77,8 & 100,0 & $3.963,2$ \\
Crianças (0 a 3) & 11,8 & 17,4 & 74,8 & 100,0 & $14.964,4$ \\
Total Urbano & & 22,2 & 66,2 & 100,0 & $1.209,9$ \\
Domicílios & 11,0 & 22,5 & 66,5 & 100,0 & $25.686,5$ \\
Pessoas & 13,9 & 24,9 & 61,2 & 100,0 & $104.482,9$ \\
Crianças (0 a 3) & 22,9 & 28,4 & 48,7 & 100,0 & $8.879,2$ \\
\hline
\end{tabular}

(*) I-indigentes; $\mathrm{Pn}$ - pobres não-indigentes, e $\mathrm{Np}$ - não-pobres.

Fonte: Pnsn; elaboração Nepp/Unicamp, 1993.

Ademais, os dados mostram extrema desigualdade na distribuição da pobreza pelas várias regiôes urbanas do Brasil. Para citar apenas alguns dados: enquanto mais de $40 \%$ das crianças nordestinas são indigentes, e duas em três são pobres, indigentes ou não, no Sul as proporções correspondentes são apenas $12 \mathrm{e}$ $34 \%$. Voltaremos à questão ao tratar da população em extrema pobreza.

A tabela 4 demonstra a precariedade habitacional dos pobres, sobretudo dos indigentes, e principalmente as desvantagens demográficas em que estão situados face ao resto da população. Os seus encargos familiares são sempre muito superiores aos dos não-pobres e a sua composição etária é freqüentemente muito mais desfavorável. Todas essas condiçôes negativas acentuam-se sobremaneira na grande região mais pobre do país (Norte, Nordeste e Centro-Oeste), onde chega a haver 1,8 pessoas em idades inativas por pessoa em idade ativa entre as famílias indigentes! As informações de relevância econômica constantes da tabela 5 contam a mesma história: base educacional quase inexistente de amplas proporçōes 
de indigentes e pobres não-indigentes, elevadas porcentagens de trabalho altamente precário (no qual o emprego de chefes de domicílios sem carteira de trabalho quase chega ou ultrapassa à metade do total de ativos) e proporçôes também apreciáveis de domicílios sem ocupados ou de pessoas desempregadas. Todas estas condições desfavoráveis são piores entre os domicílios indigentes comparados com os pobres não-indigentes, ou domićlios do Nordeste quando comparados com os do Sudeste.

Tabela 4

Brasil urbano, 1989. Seleção de características fortemente associadas à indigência e à pobreza urbanas, por grandes regiões

\begin{tabular}{|c|c|c|c|c|}
\hline Grande região & 1 & $\mathrm{Pn}$ & $\mathrm{Np}$ & Total \\
\hline \multicolumn{5}{|l|}{ Norte, Centro-Oeste e Nordeste } \\
\hline Piso inadequado (2) & $23,1 \%(1)$ & $10,3 \%$ & $2,4 \%$ & $8,9 \%\left({ }^{* *}\right)$ \\
\hline Situação sanitária má (3) & $64,4 \%$ & $42,9 \%$ & $13,2 \%$ & $32,3 \%\left({ }^{\star *}\right)$ \\
\hline $\begin{array}{l}\text { Pessoas de } 0-9 \text { anos p/domicílio } \\
\text { Indicador da composição etária }\end{array}$ & 2,10 & 1,17 & 0,78 & $1,16\left(^{*}\right)$ \\
\hline do domicílio(4) & 1,81 & 1,22 & 0,77 & $1,10\left(^{*}\right)$ \\
\hline \multicolumn{5}{|l|}{ Sudeste e Sul } \\
\hline Piso inadequado (2) & $9,2 \%(1)$ & $3,2 \%$ & $3,0 \%$ & $1,7 \%\left({ }^{* *}\right)$ \\
\hline Situação sanitária má (3) & $30,5 \%$ & $10,5 \%$ & $3,0 \%$ & $6,4 \%\left(^{* \star}\right)$ \\
\hline $\begin{array}{l}\text { Pessoas de 0-9 anos p/domicílio } \\
\text { Indicador da composição etária }\end{array}$ & 1,54 & 1,16 & 0,65 & $0,81\left(^{*}\right)$ \\
\hline do domicílio(4) & 1,40 & 1,17 & 0,70 & $0,83\left({ }^{*}\right)^{*}$ \\
\hline \multicolumn{5}{|c|}{$\begin{array}{l}\text { 1-indigentes; Pn-pobres não-indigentes; } \mathrm{Np} \text { - não-pobres. } \\
\left({ }^{*}\right) \text { porcentagem dos indigentes } 1,5 \text { a } 2 \text { vezes a média para o total. } \\
{ }^{* *} \text { relação com a média total superior a dois. } \\
\text { (1) porcentagem dos domićlios do nível de pobreza indicado, que têm a característica em questão. } \\
\text { (2) piso de terra ou de madeira aproveitada. } \\
\text { (3) sem vaso sanitário ou vaso que não é de cerâmica. } \\
\text { (4) número de pessoas em idade inativa por pessoa em idade ativa: pessoas de } 0 \text { a } 17 \text { anos e de mais de } \\
60 \text { anos por pessoa de } 18 \text { a } 59 \text { anos. } \\
\text { Fonte Pnsn; elaboração Nepp/Unicamp, } 1993 \text {. }\end{array}$} \\
\hline
\end{tabular}

Focalizemos agora os mais pobres entre os pobres, delimitados de duas maneiras: agrupando os domicílios de cada região com renda familiar per capita inferior à sua linha de indigência; e separando aqueles domićlios pobres - indigentes ou não - que não têm necessidades básicas satisfeitas (ver nota 1). Trataremos esses dois conjuntos de domićlios (que, como pode se observar, são em parte superpostos) tanto em termos de sua localização urbano-rurais quanto regionais, bem como de sua distribuição por tipo de estruturas familiares. 
Tabela 5

Brasil urbano, 1989.

Seleção de características sócio-econômicas

fortemente associadas à indigência e à pobreza,

regiōes Nordeste e Sudeste

(em \%)

\begin{tabular}{|c|c|c|c|c|c|}
\hline Região & 1 & $\mathrm{Pn}$ & & $\mathrm{Np}$ & Total \\
\hline \multicolumn{6}{|l|}{ Nordeste } \\
\hline chefes analfabetos & 58,7 & 44,6 & & 17,3 & $35,2\left(^{\star}\right)$ \\
\hline $\begin{array}{l}\text { chefes com ocupação agrícola } \\
\text { chefes empregados sem }\end{array}$ & 7,0 & 2,4 & & 1,4 & $2,9\left(^{\star \star}\right)$ \\
\hline carteira de trabalho & 55,6 & 46,9 & & 29,7 & 40,7 \\
\hline domicílios com zero ocupados & 19,1 & 16,0 & & 7,0 & $12,5\left(^{*}\right)$ \\
\hline pessoas desocupadas & 9,7 & 5,2 & & 4,0 & $5,8\left(^{*}\right)$ \\
\hline Sudeste & & - & & & \\
\hline chefes analfabetos & 34,1 & 19,9 & & 6,7 & $11,4\left(^{* *}\right)$ \\
\hline $\begin{array}{l}\text { chefes com ocupação agrícola } \\
\text { chefes empregados sem }\end{array}$ & 17,4 & 6,1 & & 0,6 & $2,7\left(^{* *}\right)$ \\
\hline carteira de trabalho & 49,5 & 25,2 & $\bullet$ & 18,5 & $21,8\left(^{* *}\right)$ \\
\hline domicílios com zero ocupados & 10,2 & 6,5 & & 7,0 & 7,1 \\
\hline pessoas desocupadas & 13,1 & 8,4 & & 3,3 & $5,1\left(^{* \star}\right)$ \\
\hline
\end{tabular}

1-indigentes; $P n$ - pobres não-indigentes; e Np - não-pobres.

${ }^{*}$ ) porcentagem dos indigentes 1,5 a 2 vezes a média para o total.

(*) relação com a média total superior a dois.

Fonte: Pnsn; elaboração Nepp/Unicamp, 1993.

Tabela 6

Brasil urbano e rural, 1989:

distribuição percentual de pobres em nível de

indigência e de pobres estruturais, pelo contínuo urbano-rural

\begin{tabular}{llcc}
\hline & Localização: & $\begin{array}{c}\text { \% pobres } \\
\text { indigentes }\end{array}$ & $\begin{array}{c}\text { \% pobres } \\
\text { estruturais }\end{array}$ \\
\hline Urbano & Metropolitano & 5,3 & 13,2 \\
& Não-metropolitano & 40,1 & 39,5 \\
& Subtotal & 55,4 & 52,7 \\
Rural & & 44,6 & 47,3 \\
Total (milhares) & $100,0 \%$ & $100,0 \%$ \\
& $24.739,1 \%$ & $32.235,0$ \\
\hline
\end{tabular}

Fonte: Pnsn, Elaboração Nepp/Unicamp, 1994. 
Tabela 7

Brasil urbano e rural( $\left.{ }^{\star}\right), 1989$ : distribuição percentual de pobres em nível de indigência e de pobres estruturais $\left(^{* \star}\right)$, por regiões

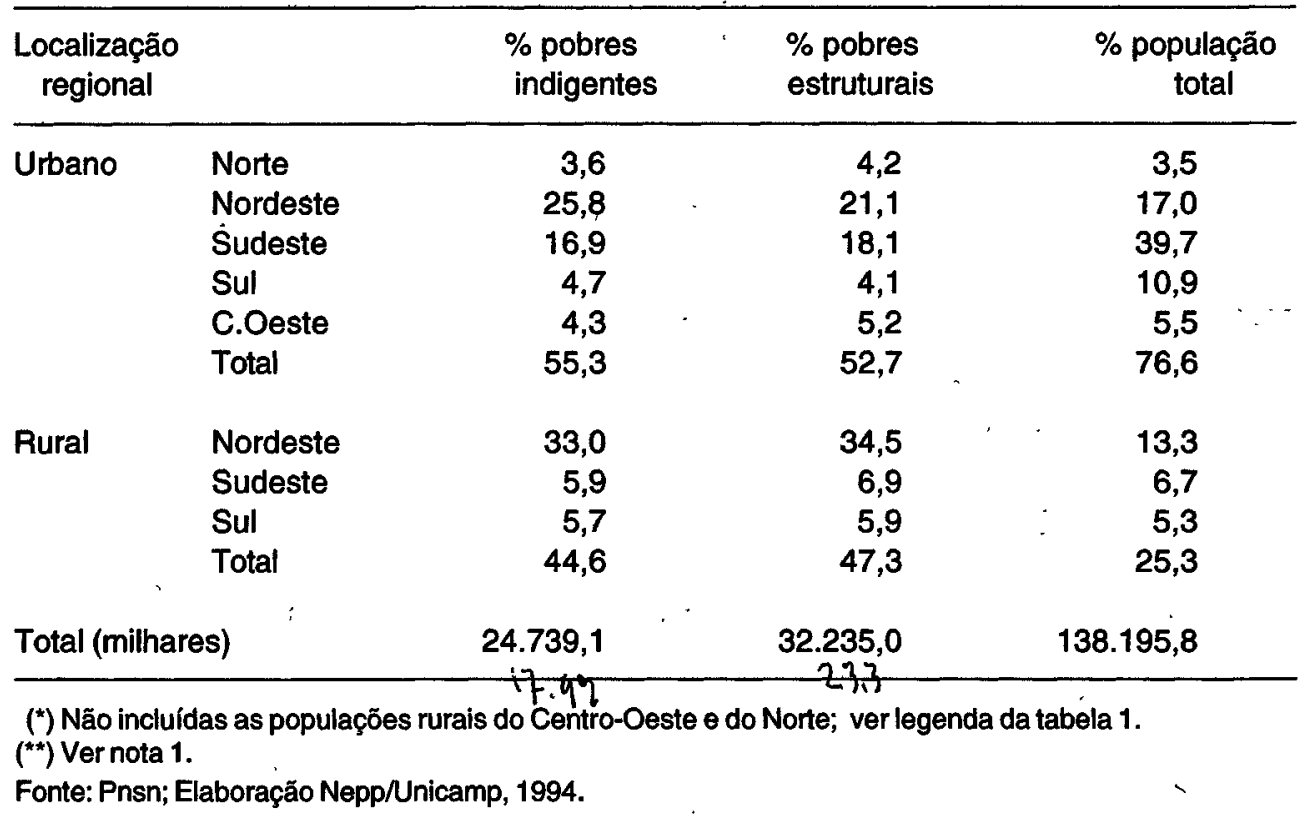

Tabela 8

Brasil urbano e rural, 1989: probabilidades( $\left.{ }^{*}\right)$ de domicílios serem de pobres indigentes ou de pobres estruturais, segundo a sua estrutura familiar

\begin{tabular}{lcc}
\hline Estruturas Familiares(**) & $\begin{array}{c}\text { Domicílios } \\
\text { indigentes }\end{array}$ & $\begin{array}{c}\text { Domicílios } \\
\text { de pobreza } \\
\text { estrutural }\end{array}$ \\
\hline Homens ou mulheres, sós, jovens, (-34) & 0,5 & 0,9 \\
Casais sós, jovens (-34) & 2,5 & 4,5 \\
Casais jovens (-34), com filhos e outros & 16,5 & 24,5 \\
Casais (35 a 59 anos), com filhos e outros & 15,0 & 18,5 \\
Homens, mulheres, casais (60+), filhos e outros & 14,4 & 16,1 \\
Homens, mulheres, casais (60+), sós & 7,6 & 13,9 \\
Outras estruturas familiares & 5,7 & 6,4 \\
Estruturas plurifamiliares & 13,6 & 20,8 \\
Mulheres chefes, jovens (-34), sem cônjuge, & 35,7 & 33,6 \\
$\quad$ com filhos e outros & & 19,1 \\
Mulheres chefes (35 a 59 anos), sem cônjuge, & 16,7 & 18,2 \\
$\quad$ com filhos e outros & 13,9 &. \\
Total & &
\end{tabular}

(*) Porcentagens sobre o total de domicilios de cada tipo de estrutura familiar.

(**) Sobre esta classificação de estruturas familiares, ver Lopes, 1993.

Fonte: Pnsn; elaboração Nepp/Unicamp, 1994. 
Observa-se, nas três últimas tabelas, vários aspectos: em primeiro lugar, a alta concentraçăo locacional das pessoas muito pobres; quase a metade delas está nas zonas rurais (recordemos que nas nossas estatísticas não estão incluídos os habitantes rurais das regiōes Centro-Oeste e Norte! (ver legenda da tabela 1). Outros $40 \%$ encontram-se nas áreas urbanas não-metropolitanas. A extrema pobreza, embora muito visível em áreas metropolitanas, alcança apenas de 13 a 15\% do total de pobres nessa situação, bem aquém da proporção que as metrópoles representam no total da população brasileira (cerca de um quarto). Quando olhamos a distribuição da extrema pobreza pelas regióes, vemos a grande maioria no Nordeste, seja na sua parte rural $(34,5 \%)$ sejar na urbana (21\%), somando 14,6 milhóes de pessoas (cerca de $57 \%$ do total das muito pobres). Isso, numa região cuja participação na populaçảo brasileira é de apenas 30\%. Outra concentração importante ocorre nas cidades do Sudeste (onde estão $18 \%$ dos muito pobres); esta regiáo porém possui $40 \%$ da populaçáo total.

A análise da extrema pobreza segundo os tipos de estrutura familiar sugere, antes de mais nada, a diversidade de situaçóes da pobreza extrema: mais de três quintos (62 a 64\%) são domicílios com casais com filhos; são também numerosos os domicílios extremamente pobres de chefia feminina com filhos presentes (11 a 14\% do total) e as unidades domésticas plurifamiliares (8 a 9\%). Pensando em cada um desses casos, não é difícil perceber quão diferentes são as suas condições. Deve-se mencionar ainda o caso bem distinto, embora menos freqüente (3 a $4 \%$ do total), de domicílios de idosos, casais ou sós. Todas essas estruturas familiares estão entre aquelas nas quais a probabilidade de ser extremamente pobre é alta. O caso mais notável é o de mulheres jovens, sem cônjuge e com filhos; mais de um terço de todos os domicílios que estão nessa situação no país (660 mil) é muito pobre!

\section{Acesso a Programas Sociais}

A Pnsn permitiu estimular a cobertura de alguns programas sociais considerando os domićlios urbanos e rurais, separados segundo os níveis de pobreza (indigentes, pobres não-indigentes e não-pobres) ou os tipos de pobreza (estrutural, recente, pobreza por NBI, e não-pobres stricto sensu). Os programas considerados foram os nutricionais e alimentares dirigidos ao grupo materno-infantil; o acesso do grupo de sete $\mathrm{a} 14$ anos à escola de $1^{\circ}$ grau e à merenda escolar; $\mathrm{e}$, no outro extremo do ciclo vital, a obtenção de pensóes $\mathrm{e}$ aposentadorias por pessoas com 60 anos e mais.

Alguns programas, embora ainda longe de serem universais, mostram significativa cobertura dos vários níveis e tipos de pobreza, principalmente no Sul e no Sudeste. Estão nesse caso o programa pré-natal, o acesso ao primeiro grau e à 
merenda escolar e, também, por mais insuficientes que sejam os seus montantes, as pensões e aposentadorias. No outro extremo, $\mathrm{o}$ acesso das populaçóes pobres a creches e, sobretudo, a programas de distribuição gratuita de alimentos, é muito menor e incerto. Vejamos:

\section{Programas de atendimento a gestantes e nutrizes}

É significativo que mais de a metade das gestantes de domicílios indigentes do Sul e Sudeste, como também três em quatro das de domicílios pobres nãoindigentes, façam pré-natal (as proporções correspondentes para as outras regiōes mais pobres do país são bem mais baixas: 30 e 47\%). No Norte, Nordeste e Centro-Oeste as porcentagens de gestantes indigentes inscritas em programas de alimentação beiram os $20 \%$ enquanto, para esses programas, as porcentagens para a parte mais rica do país são muito inferiores, embora atingindo também mais fortemente as residentes em domicilios indigentes e pobres. Ou seja, os programas nutricionais e alimentares aparecem com graus maiores de focalização para níveis e regióes mais pobres. Ocorre o inverso com os programas de atenção pré-natal que supốem melhores condições de informação, educação e oferta de serviços de saúde. Esses cobrem menos as pessoas e regiốes mais pobres. É interessante observar ainda, entre as gestantes indigentes das regióes Norte, Nordeste e Centro-Oeste, a proximidade dos percentuais de participação em programas de atenção prénatal $(29,6 \%)$ e programas de alimentação $(20,3 \%)$. Essa semelhança, muito mais acentuada que para os outros estratos e regiôes, sugere forte associação entre as açốes de saúde e alimentação, ou seja, muito provavelmente a procura pelo programa pré-natal se dá, entre as gestantes mais pobres das regióes mais pobres do país, pelo atrativo da alimentação.

\section{Programas nutricionais e alimentares, segundo nipeis e tipos de pobreza}

Os programas nutricionais e alimentares, como demonstram as tabelas a seguir, têm muito menor cobertura que os anteriores, principalmente se compararmos o número total de crianças de zero a sete anos e as que efetivamente receberam alimentos: as porcentagens são extremamente baixas variando de 12 a $20 \%$.

Examinando-se essas tabelas percebe-se que o acesso aos programas de distribuição de alimentos - seja segundo os níveis (tabela 10), seja segundo os tipos de pobreza (tabela 11) -é menor entre os mais pobres entre os pobres: entre os pobres indigentes, menor que entre os não-indigentes; também menor para os pobres estruturais, do que para os pobres recentes. Aliás, os diferenciais regionais que quase sempre encontramos no acesso aos programas sociais devem ser interpretados de forma similar, isto é, como indicando alcance menor dos programas para os 
pobres mais necessitados, para aqueles das amplas regióes menos desenvolvidas do país (Norte, Nordeste e Centro-Oeste).

Tabela 9

Brasil urbano e rural, 1989: programas de gestantes e nutrizes, pré-natal e suplementação alimentar, por grandes regiões do país e níveis de pobreza

\begin{tabular}{|c|c|c|c|c|c|}
\hline \multicolumn{2}{|c|}{$\begin{array}{l}\text { Número de } \\
\text { gestantes }\end{array}$} & $\begin{array}{l}\% \text { programa. } \\
\text { pré-natal }\end{array}$ & $\begin{array}{l}\% \text { insc. } \\
\text { prog.alim. }\end{array}$ & $\begin{array}{l}\text { Número de } \\
\text { nutrizes }\left({ }^{\star}\right)\end{array}$ & $\begin{array}{l}\% \text { insc. } \\
\text { prog. alim. }\end{array}$ \\
\hline \multicolumn{6}{|c|}{$\begin{array}{l}\text { Norte, Nordeste } \\
\text { e Centro-Oeste }\end{array}$} \\
\hline 1 & 269.073 & 29,6 & 20,3 & 577,859 & 19,9 \\
\hline Pn & 204.807 & 46,9 & 17,8 & 319.548 & 19,5 \\
\hline $\mathrm{Np}$ & 287.514 & 62,6 & 12,3 & 412.531 & 11,1 \\
\hline Total & 761.394 & 46,7 & 17,8 & 1.309 .938 & 17,0 \\
\hline \multicolumn{6}{|c|}{ Sul e Sudeste } \\
\hline 1 & 110.794 & 51,0 & 2,3 & 266.028 & 8,6 \\
\hline $\mathrm{Pn}$ & 220,172 & 75,9 & 7,6 & 509.787 & 10,1 \\
\hline $\mathrm{Np}$ & 558,306 & 82,1 & 2,4 & 972.608 & 4,6 \\
\hline Total & 889.272 & 76,7 & 3,7 & 1.748 .423 & 6,8 \\
\hline \multicolumn{6}{|l|}{ Brasil } \\
\hline I & 379.867 & 35,8 & 15,1 & 843.887 & 16,3 \\
\hline $\mathrm{Pn}$ & 424.979 & 61,9 & 12,5 & 829.335 & 13,7 \\
\hline NP & 845.820 & 75,5 & 5,8 & 1.385 .139 & 6,5 \\
\hline Total & 1.650 .666 & 62,9 & 9,7 & 3.058 .361 & 11,2 \\
\hline
\end{tabular}

(*) Mulheres com filhos de menos de um ano.

Fonte: Pnsn; elaboração Nepp/Unicamp, 1993.

Tabela 10

Brasil urbano e rural, 1989: proporções de crianças de zero a sete anos inscritas, e que nas últimas quatro semanas receberam alimentos em programas de distribuição gratuita, por níveis de pobreza e segundo o local em que recebem os alimentos

\begin{tabular}{lrrrr}
\hline & \multicolumn{1}{c}{ I } & \multicolumn{1}{c}{$\mathrm{Pn}$} & \multicolumn{1}{c}{$\mathrm{Np}$} & \multicolumn{1}{c}{ Total } \\
\hline № crianças (0-7) & 7.713 .779 & 6.765 .971 & 11.600 .690 & 25.880 .440 \\
№ inscritas & 1.542 .450 & 1.676 .610 & 1.115 .615 & 4.334 .675 \\
№ que recebeu & 956.414 & 1.375 .606 & 853.698 & 3.185 .718 \\
\% crianças que recebeu & $12,7 \%$. & $20,3 \%$ & $7,4 \%$ & $12,3 \%$ \\
\% Padaria, armazém & $35,0(1)$ & $62,5(1)$ & $66,8(1)$ & $55,4(1)$ \\
\% Centro de saúde & 30,7 & 13,9 & 10,9 & 18,1 \\
\% Ass. comunitária & 13,8 & 9,1 & 9,1 & 10,5 \\
\% Igreja, paróquia. & 5,8 & 2,6 & 2,2 & 3,5 \\
\% Prefeitura & 2,0 & 1,5 & 0,6 & 1,4 \\
\% Outros & 11,3 & 7,9 & 4,8 & 8,1 \\
\% Atendim. Saúde & 43,4 & 35,7 & 33,5 & 37,4 \\
\hline
\end{tabular}

(1) Porcentagens calculadas sobre o número de crianças que recebeu alimentos.

Fonte: Pnsn; elaboração Nepp/Unicamp, 1993. 
Tabela 11

Brasil urbano e rural, 1989: proporções de crianças

de zero a sete anos inscritas e que, nas últimas quatro semanas, receberam alimentos em programas de distribuição gratuita,

por tipos de pobreza*

\begin{tabular}{lrrrrr}
\hline & $\begin{array}{c}\text { Pobre } \\
\text { estrutural }\end{array}$ & $\begin{array}{c}\text { Pobre } \\
\text { recente }\end{array}$ & $\begin{array}{c}\text { Pobre } \\
\text { por NBI }\end{array}$ & $\begin{array}{c}\text { Np } \\
\text { Scricto Sensu }\end{array}$ & Total \\
\hline Crianças & 9.390 .265 & 4.885 .197 & 3.091 .704 & 8.499 .406 & 25.866 .572 \\
Inscritas & 2.048 .178 & 1.169 .108 & 418.272 & 697.343 & 4.332 .901 \\
$\begin{array}{l}\text { Receberam } \\
\text { \% crianças }\end{array}$ & 1.346 .349 & 983.891 & 301.410 & 552.288 & 3.183 .938 \\
que receberam & $14.3 \%$ & $20,1 \%$ & $9,7 \%$ & $6.5 \%$ & $12,3 \%$ \\
\hline
\end{tabular}

* ver nota 1.

Fonte: Pnsn; elaboração Nepp/Unicamp, 1993.

As informações básicas apresentadas neste estudo registram um dado positivo, significativo do esforço de atuação sobre as condiçốes de saúde, mesmo presumindo-se o atrativo do alimento: das crianças pobres que receberam alimentos, mais de $1 / 3$ recebeu também algum atendimento de saúde (43,4\% das indigentes; $35,7 \%$ das pobres não-indigentes; $33,4 \%$ das nãopobres e $37,4 \%$ do total.

\section{Acesso a creches, a escola do primeiro gran e a merenda escolar}

As tabelas 12 e 13 fornecem dados sobre o acesso a creches e ao primeiro grau, além de indicarem a disponibilidade ou não de merenda escolar.

Em 1989, o país continuava a mostrar números muito baixos de matrículas de crianças de zero a seis anos em creches e escolas maternais principalmente entre crianças pertencentes a domicílios pobres - ainda que se saiba ter essa cobertura crescido a altas taxas durante os anos 80 . A tabela 12 revela ainda, entre os pobres que vão à escola, as altas taxas de freqüência em creches gratuitas, nas quais quase todas as crianças recebem merenda.

Os dados da tabela 13 indicam ser amplo o acesso ao primeiro grau escolar. Nota-se ainda que as desigualdades regionais acentuam-se sobremaneira quanto ao acesso à escola pública quando se observa o aspecto de esta oferecer ou não merenda escolar. Assim, para o grupo de pobres em 
situação de indigência, a desvantagem da grande região mais pobre (Norte, Nordeste e Centro-Oeste) com relaçấo ao Sul e Sudeste, que é de dez pontos percentuais quanto ao acesso à escola pública, passa para 33 pontos, quando a pergunta refere-se à escola oferecer merenda (4). Outras informações coletadas através da Pnsn mostram também que, com relação à freqüência à escola, as proporçóes de crianças de sete a 14 anos das zonas rurais na grande região menos desenvolvida do país (Norte, Nordeste e Centro-Oeste), embora mais baixas do que as das rurícolas do Sul e do Sudeste (diferencial de dez a 16 pontos percentuais) já são significativas: três em cinco crianças daquele grupo etário já freqüientam a escola; as proporções nas zonas urbanas e em outras regiōes são bem mais altas. Nas zonas urbanas do Sul e Sudeste, 80 a $\mathbf{8 8 \%}$ dessas crianças estão na escola (5). Grandes contingentes de meninos e meninas entre sete e 14 anos têm assim acesso ao maior e mais universal programa de distribuição gratuita de alimentos, o da merenda escolar.

Tabela 12

Brasil urbano e rural, 1989: crianças que freqüentam creche ou maternal e têm merenda gratuita, por niveis de pobreza

\begin{tabular}{|c|c|c|c|c|c|c|}
\hline $\begin{array}{l}\text { Grupo } \\
\text { etário }\end{array}$ & & $\begin{array}{l}N^{0} \text { de } \\
\text { crianças }\end{array}$ & & $\begin{array}{l}\text { \% Freq. } \\
\text { à escola }\end{array}$ & $\begin{array}{l}\% \text { creches } \\
\left.\text { gratuitas( }{ }^{*}\right)\end{array}$ & $\begin{array}{c}\% \text { recebimento } \\
\text { merenda }\left({ }^{*}\right)\end{array}$ \\
\hline Pobres $(1+P n)$ & & . & . & & $\cdot$ & . \\
\hline 0 a 3 anos & & 5.328 .913 & & 2,1 & 79,0 & 89,1 \\
\hline$>3$ a 4 anos & & 1.601 .345 & & 6,9 & 81,0 & 86,6 \\
\hline 4 a 6 anos & & 5.280 .331 & & 22,9 & 75,1 & \# \\
\hline Total & & 12.210.589 & $\cdot$ & 11,7 & 75,8 & \# \\
\hline Pobres (Np) & & - & & & & \\
\hline 0 a 3 anos & $\cdot$ & 4.222.306 & & 4,4 & 21,8 & 25,2 \\
\hline$>3$ a 4 anos & & 1.304 .683 & & 18,9 & 20,2 & 19,1 \\
\hline 4 a 6 anos & & 4.285 .791 & & 45,5 & 46,4 & $\therefore \#$ \\
\hline Total & & 9.812 .780 & & 24,3 & 41,7 & $\#$ \\
\hline Total & & & & & . & \\
\hline 0 a 3 anos & & 9.551 .219 & & 3,2 & 43,4 & 49,2 \\
\hline$>3$ a 4 anos & . & 2.906 .028 & . & 12,3 & 39,0 & 39,0 \\
\hline 4 a 6 anos & 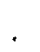 & 9.566 .122 & & 33,0 & 57,3 & . $\#$ \\
\hline Total & & 22.023.369 & & 17,3 & 54,5 & \# \\
\hline
\end{tabular}

* Porcentagens calculadas sobre o número que frequienta escola.

\# Não existe o dado.

Fonte: Pnsn; elaboração Nepp/Unicamp, 1993. 
Tabela 13

Brasil urbano e rural: proporções de crianças de sete a 14 anos que freqüentam à escola, discriminando se a escola é pública e se nela recebem merenda, por grandes regiōes e segundo níveis de pobreza

\begin{tabular}{lrccc}
\hline $\begin{array}{l}\text { Níveis de } \\
\text { pobreza }\end{array}$ & $\begin{array}{c}\text { No de } \\
\text { crianças }\end{array}$ & $\begin{array}{c}\text { \% na } \\
\text { escola }\end{array}$ & $\begin{array}{c}\text { \% escola } \\
\text { pública }\end{array}$ & $\begin{array}{c}\text { \% recebem } \\
\text { merenda }\end{array}$ \\
\hline $\begin{array}{l}\text { Grande Região Norte, } \\
\text { Nordeste e Centro-Oeste }\end{array}$ & & & & \\
I & 4.565 .979 & 68,0 & 66,7 & 43,2 \\
Pn & 3.063 .048 & 79,5 & 71,6 & 53,4 \\
Np & $3,424.534$ & 84,5 & 59,0 & 39,9 \\
Total & 11.053 .561 & 76,5 & 65,6 & 45,0 \\
& & & & \\
Grande Região Sul e Sudeste & & & & \\
I & 2.152 .950 & 78,1 & 76,4 & 75,8 \\
Pn & 4.241 .996 & 85,1 & 78,6 & 75,8 \\
Np & 9.050 .923 & 91,0 & 72,9 & 77,4 \\
Total & 15.445 .869 & 87,6 & 75,0 & 70,2 \\
Brasil & & & & \\
I & & & & \\
Pn & 6.718 .929 & 71,5 & 69,8 & 52,2 \\
Np & 7.305 .044 & 82,8 & 75,7 & 66,4 \\
Total & 12.475 .457 & 89,3 & 69,1 & 59,8 \\
\hline
\end{tabular}

Fonte: Pnsn; elaboração Nepp/Unicamp, 1993.

\section{Seguridade social: pensóes e aposentadorias}

As tabelas 14 e 15 incluem informaçóes sobre o acesso dos idosos às pensões e aposentadorias, segundo as grandes regióes, a sua localização urbana e rural, e se ainda estão trabalhando. Como se constata, de 65 a 70\% (nos níveis de indigência e de pobreza não-indigente, respectivamente) daqueles com mais de 60 anos recebem pensões e/ou aposentadoria, num total de 4,1 milhões de pessoas. As proporçôes regionais não diferem significativamente (embora haja maior proporção de pensões no Sul e Sudeste do que nas outras regiốes, contrabalançada por menor proporção de aposentadorias). Por outro lado, há diferenciais apreciáveis na ocorrência de pensões e aposentadorias entre os sexagenários que ainda. estão trabalhando: bem menores as proporçôes do que entre aqueles do mesmo grupo que não trabalham. Ficamos entre duas interpretações distintas: deve-se isso ao fato de que, para muitos, as ínfimas pensões e aposentadorias os obrigam a continuar trabalhando, por precário e pequeno que seja o ganho adicional? $\mathrm{Ou}$, diferentemente, é a permanência no trabalho, cuja remuneração, juntada à pensão e/ou à aposentadoria, os tira dos níveis de pobreza e diminui as taxas de pensionistas e aposentados nesses níveis? Essas explicaçóes, é evidente, não são mutuamente exclusivas. Estudos de outra ordem se tornam necessários para elucidar a questão. 
Note-se ainda as proporçóes de aposentados e pensionistas segundo a localização: nos dois níveis de pobreza são quase sempre menores nas zonas rurais do que nas urbanas (à exceção dos pobres não-indigentes que trabalham, caso em que os rurícolas alcançam taxas um pouco mais elevadas de aposentados e pensionistas).

\section{Tabela 14}

Brasil urbano e rural: pensões e aposentadorias de pessoas com 60 anos de idade e mais, segundo localização urbana ou rural e se trabalham ou não, por níveis de pobreza

\begin{tabular}{lrrrrrrrr}
\hline & \multicolumn{3}{c}{ Zonas Urbanas: } & \multicolumn{7}{c}{ Zonas Rurais: } \\
& Ocup. & P\& & Não & P\& & Ocup. & \multicolumn{1}{c}{ P\& } & Não & P\& \\
& & Ap* & Ocup. & AP* & & Ap* & Ocup.* & Ap \\
\hline I & 124.096 & 48,5 & 650.343 & 70,8 & 231.495 & 38,7 & 344.850 & 66,2 \\
Pn & 571.950 & 45,0 & 1.443 .914 & 87,4 & 162.906 & 53,0 & 281.610 & 74,5 \\
Np & 1.442 .860 & 52,7 & 3.829 .404 & 75,6 & 735.150 & 50,8 & 899.855 & 70,7 \\
Total & 2.138 .906 & 50,4 & 5.923 .661 & 75,5 & 1.129 .551 & 48,6 & $1,526.315$ & 70,4 \\
\hline
\end{tabular}

* Porcentagem de pensionistas e/ou aposentados.

Fonte: Pnsn; elaboração Nepp/Unicamp.

\section{Tabela 15}

Brasil urbano e rural: pensões e aposentadorias de pessoas com 60 anos de idade e mais, segundo grandes regiōes e por níveis de pobreza

\begin{tabular}{|c|c|c|c|c|c|c|c|c|}
\hline & \multicolumn{3}{|c|}{ N/Ne/C.Oeste } & \multicolumn{3}{|c|}{ Sul e Sudeste } & \multicolumn{2}{|l|}{ Total } \\
\hline & $\begin{array}{l}n^{\circ} \text { pessoas } \\
\text { e } 60+\end{array}$ & $\begin{array}{r}P \\
\left({ }^{*}\right)\end{array}$ & Ap & $\begin{array}{l}n^{\circ} \text { pessoas } \\
\text { de } 60+\end{array}$ & $\mathbf{P}$ & $\begin{array}{l}\text { Ap } \\
\left({ }^{*}\right)\end{array}$ & $\begin{array}{c}n^{\circ} \text { pessoas } \\
\text { de } 60+\end{array}$ & $\begin{array}{c}\text { P\& Ap } \\
\left({ }^{\star *}\right)\end{array}$ \\
\hline 1 & 941.055 & 3,0 & 59,1 & 524.492 & 7,0 & 63,4 & 1.465 .547 & 65,1 \\
\hline Pn & 1.286 .232 & 4,6 & 68,8 & 1.360 .340 & 13,3 & 53,8 & 2.648.572 & 70,2 \\
\hline $\mathrm{Np}$ & 1.944 .176 & 5,4 & 62,6 & 5.309 .473 & 13,1 & 56,4 & 7.253 .649 & 69,1 \\
\hline Total & 4.171 .463 & 4,6 & 63,7 & 7.194.305 & 12,7 & 56,4 & 11.365 .768 & 68,8 \\
\hline
\end{tabular}

* P - \% pensionistas; Ap - \% aposentados (inclusive pessoas que são aposentadas $\Theta$ pensionistas).

** \% de pensionistas e/ou aposentados.

Fonte: Pnsn; elaboração Nepp/Unicamp.

Merecem ainda registro alguns dados sobre os idosos que não recebem qualquer auxílio previdenciário - cerca de $31 \%$ do total. São 3,5 milhões de 
pessoas com 60 anos e mais que não recebem benefícios da Previdência, dos quais mais de meio milhão são pobres em nível de indigência e quase 800 mil, pobres não-indigentes. Entre esses pobres, indigentes ou não, mais de 700 mil não trabalham e, portanto, com grande probabilidade, não dispóem de rendimento algum.

\section{A questão do mistargetting}

A análise dos programas sociais mostrou-nos que o acesso a eles, muitas vezes, é menor, proporcionalmente, para os mais pobres entre os pobres (os indigentes ou os pobres estruturais) do que para os não tão pobres. O estudo dos dispêndios sociais com uma gama mais ampla de programas, segundo as várias faixas da população atingida, evidencia as distorções muito maiores da situação social brasileira. Documento do Banco Mundial em 1988, usando dados de 1985, apresenta-nos num exercício "estimativas heurísticas da renda e perfis de benefícios... combinadas com dados de surveys de domicílios [servem] para ilustrar como benefícios [saúde, serviços de água e esgoto, habitação, urbanismo, trabalho, transporte urbano, alimentação e nutrição, e previdência social] são provavelmente distribuídos". Este exercício mostra que os mais pobres, quase um quinto da população recebem apenas $7 \%$ do total de benefícios, enquanto no outro extremo da distribuição, cerca de $4 \%$ dos de maior renda recebem aproximadamente $18 \%$ daquele total.

Notas

1 Os dados que constam das tabelas apresentadas neste texto, bem como os de Lopes (1993, 1994), construídos a partir da fita da Pesquisa Nacional de Saúde e Nutrição Pnsn, do Inan/Ibge/Ipea de 1989, utilizam linhas de indigência e pobreza calculadas a partir dos valores obtidos por Rocha (1991) para as regiōes metropolitanas brasileiras. Rocha chegou aos seus valores a partir da atualização de preços das cestas básicas dos extratos de baixa renda da pesquisa de orçamentos familiares do Endef e o coeficiente de Engel do $4^{\circ}$ decil. Lopes (1993), em um de seus estudos, chegou a valores das linhas de indigência e pobreza para as populaçóes urbana não-metropolitana, urbana total e rural, de cada regiâo do país, pela extrapolação dos dados das regióes metropolitanas dessas regióes. Usou, para tanto, dados de população e valores das cestas alimentares e nãoalimentares constantes do Endef (ver Fava, 1984). Este era o único procedimento possível já que não existe no Brasil série de preços de áreas não metropolitanas e muito menos de áreas rurais. Os valores obtidos, em dólares mensais per capita, das linhas de - indigência e pobreza respectivamente, para cada região, são os seguintes: Sul (urbanas: US\$ 19,3 e 38,9; rurais: US\$ 14,7 e 23,7); Sudeste (US\$ 20,4 e 18,4: rurais: US\$ 13,1 e 20,7); Nordeste (US\$ 16,4 e 35,4; rurais US\$12,9 e 19,0); e Norte e CentroOeste, onde só foi possível calcular as linhas para as áreas urbanas, US\$22,9 e 54,4. Construiu-se também um indicadox̊de necessidades básicas satisfeitas (NBS) ou não (NBI), a partir de seis variáveis, quatro das quais referem-se a qualidades da habitação (tal como a existência ou não de esgotamento sanitário), além de densidade do uso dos dormitórios e presença ou não de crianças em idade escolar que não freqüientam a 
escola. Para classificar-se um domicílio como NBI basta uma única das variáveis situarse em má situação, mesmo que as demais classifiquem-se como satisfeitas (mais detalhes sobre este indicador, ver Lopes, 1993). O cruzamento do indicador NBI/NBS com aquele que separa a população segundo a linha de pobreza, permite uma aproximação da pobreza estrutural, separadamente da pobreza mais recente resultado da crise dos anos 80. Quatro tipos de pobreza são obtidos por esta metodologia: pobreza estrutural, em que as famílias se encontram abaixo da linha de pobreza e com necessidades básicas insatisfeitas (pelo menos $12 \%$ do total dos domicílios, em 1989, segundo os dados da Pnsn); pobreza mais recente, na qual as famílias se encontram abaixo da linha de pobreza, mas ainda mantêm necessidades básicas satisfeitas ( $21 \%$ do total); pobreza por NBI, em que famílias, embora situando-se acima da linha da pobreza, não conseguem ter necessidades básicas satisfeitas (pelo menos $6 \%$ do total); e, finalmente, os não-pobres, stricto sensu, ou seja, famílias acima da linha de pobreza e com suas necessidades básicas satisfeitas (60\% do total).

2 Estudo mais recente realizado por Sonia Rocha para áreas metropolitanas, nos fornece proporção de pobres em 1990 quase igual ao que se tinha no início dos anos 80 (Rocha, 1992:4). Como nos últimos anos temos distribuição de renda muito pior do que no início dos 80 (ver Bonelli \& Sedlacek, 1991), isto é consistente, entre coisas, com uma desigualdade maior entre os pobres, que por sua vez pode resultar do aumento da pobreza (pobreza recente) nos anos recessivos da década.

3 As linhas de pobreza rurais são claramente subestimadas, sendo, como são, extrapoladas a partir de dados de há quase $\mathbf{2 0}$ anos. $\mathrm{O}$ métodos de extrapolação pressupóe que o custo de vida rural evoluiu como o metropolitano, quando provavelmente nas zonas rurais ele subiu mais rapidamente. Em nosso estudo, o número total de domicílios em nível de indigência, urbanos e rurais, é 4,7 milhões, abrangendo 25,6 milhões de pessoas (Lopes, 1993). Cálculos recentes baseados na Pnad de 1990, feitos pela Coordenação de Política Social do Ipea, e usados para fundamentar o Programa de Combate à Fome e à Miséria, chegam a números de pessoas em estado de indigência no Brasil bem maiores: 9 milhões de famílias e 32 milhốes de pessoas. A conceituação de indigência ("pessoas cuja renda familiar corresponde, no máximo, ao valor da aquisição de cesta básica de alimentos que atenda, para a família como um todo, os requerimentos nutricionais recomendados pela FAO/OMS/ONU'), e a metodologia dos cálculos são, grosso modo, as mesmas empregadas tanto neste estudo quanto no de Lopes (1993). A metodologia consiste, em última análise, na comparação de cálculo dos valores dessas linhas. Os dados existentes para tal cálculo são antigos (Endef, 1974/75) e somente existem informações adequadas (POFs - Pesquisas de Orçamento Doméstico e séries de preços), quanto à sua atualização para as áreas não-metropolitanas e rurais com base nas respectivas linhas das zonas metropolitanas. No caso do estudo da CPS/Ipea essas estimativas parecem ser feitas com bastante critério e sofisticação. Ver Peliano (coord.), mar. 1993 e abr. 1993.

4 Assinale-se que a merenda na região mais pobre é um programa apenas da União, sem a participação dos estados e municípios, enquanto no Sul e Sudeste a participação desses últimos é significativa.

5 No nível de indigência, as proporções de crianças daquele grupo etário nas zonas urbanas e rurais são, respectivamente, 77 e 63\%; no nível dos pobres não-indigentes, 88 e $65 \%$. 
Referências bibliográficas

BANCO MUNDIAL. Brasil: public spending on social programs: issues and options, v. 1, May 271988.

BONELLI, R \& SEDLACEK, G.L. A evolução da distribuição de renda entre 1983 e 1988. In: J.M. Camargo \& F. Giambiagi, Distribuição de renda no Brasil. São Paulo, Paz e Terra, 1991, p. 47-68.

FAVA, V.L. Urbanização, custo de vida e pobreza no Brasil. São Paulo: IPE/USP, 1984.

LOPES, J.R.B. A população pobre e o acesso a programas sociais. Estratégias para combater a pobreza no Brasil: programas, instituiḡôs e recursos (versão preliminar do Relatório Final). Campinas, Núcleo de Estudos de Políticás Públicas, mar. 1994.

- Brasil 1989: um estudo sócio-econômico da indigência e da pobreza urbanas. Cadernos NEPP n. 25. Campinas, Núcleo de Estudos de Políticas Públicas, 1993.

PELIANO, Anna Maria T.M. (coord.). O mapa da fome II: informafōes sobre a indigéncia por municipios da Federaf̧ão. Documento de Política $n^{2} 15$. Brasília, Ipea: Instituto de Pesquisa Econômica e Aplicada, abr. 1993.

- O mapa da fome: subsidios à formulação de uma politica de segurança alimentar. Documento de Política no 14. Brasília, Ipea: Instituto de Pesquisa Econômica e Aplicada, mar. 1993.

ROCHA, S. Pobreza metropolitana e os ciclos de curto prazo: um balanço dos anos 80. Ipea, Boletim Conjuntural n. 12, jan. 1991, p. 35-39.

. Poor and non poor in the brazilian labor market. Texto para Discussão n. 278. Rio de Janeiro, Ipea, out. 1992.

ROMÃO, M. Distribuição de renda, pobreza e desigualdades regionais no Brasil. In: J.M. Camargo \& F. Giambiagi, Distribuiçũo de renda no Brasil. São Paulo, Paz e Terra, 1991, p. 97-120.

Juarez Rubens Brandão Lopes é professor do Instituto de Filosofia e Ciências Humanas e pesquisador do Núcleo de Estudos de Políticas Públicas da Unicamp.

Este paper baseia-se, em parte, em estudos anteriores do autor, feitos no Núcleo de Estudos de Políticas Públicas - Nepp da Unicamp: Brasil 1989: um estudo sócio-econômico da indigência e da pobreza urbanas. Cadernos NEPP n. 25, Campinas, Núcleo de Estudos de Políticas Pública, 1993; A populaçăo pobre e o acesso a programas sociais, em Estratégias para combater a pobreza no Brasil: programas, instituiç̃os e recursos (versão preliminar do Relatório Final). Campinas, Núcleo de Estudos de Políticas Públicas, mar. 1994. As tabelas básicas deste estudo foram preparadas competentemente por Stella Maria Barbará Silva Telles. 